$1.5 \%$ agarose gel stained with ethidium bromide.

The seroprevalence rate in the first set of virus neutralization assays in Vero cells was $14 / 20(70 \%$, with titers ranging from $1: 20$ to $1: 320[3 \times 1: 20$, $3 \times 1: 40,3 \times 1: 80,2 \times 1: 160,3 \times 1: 320]$ ). No differences were discernible in either the seroprevalence rate or in the average titers of crocodiles from two different breeding farms. In $\mathrm{BHK}$ cells, a similar seroprevalence rate was observed, with titers ranging from $1: 40$ to $1: 1,280 \quad(3 \times 1: 40,2 \times 1: 80$, $1 \times 1: 160, \quad 4 \times 1: 320, \quad 3 \times 1: 640$, 1x1:1280). All serum samples, except one, were $<1: 10$ against ITV virus, which had a titer of 1:640 against WNV and 1:10 against ITV. Viremia was not detected in any of the 20 samples in Vero cell culture or by RT-PCR.

These results demonstrate a high rate of infection with WNV in crocodiles in Israel. The crocodiles may have been exposed to the virus during the summer at their present location, since no difference in prevalence was seen between the two groups (which differed only in the farm of origin) and since the younger crocodiles had been hatched in the spring of 2002 . Furthermore, a cross-reaction with the other prevalent flavivirus in Israel, ITV, was ruled out. Preliminary results from an equine seroprevalence study (involving 800 horses over a 3year period) of virus neutralization antibodies to WNV collected during fall 2002, indicate that most horses sampled in Israel's Arava Valley (a desert in the Syrian-African Rift near the Jordanian and Egyptian borders) and the Gulf of Aqaba/Eilat $\left(30^{\circ} 59^{\prime} \mathrm{N}\right.$, $35^{\circ} 18^{\prime} \mathrm{E}$ to $\left.29^{\circ} 34^{\prime} \mathrm{N}, 34^{\circ} 57^{\prime} \mathrm{E}\right)(85 \%$, 79/90) were positive (A. Steinman and S. Tal, unpub. data,). WNV was also isolated from mosquitoes in the same region (10). The seroprevalence of WNV antibodies among horses and local birds from the Negev Desert is not known nor is the time when the horses acquired WNV infection. However, the isolation of WNV from mosquitoes (10) and the presence of antibodies to WNV in young crocodiles demonstrate arboviral activity in this region in the summer of 2002, although clinical cases were few. That virus was not isolated from crocodiles in late November (past outbreaks of WNV in Israel mainly occurred between August and October) $(6,11)$.

WNV has been endemic in Israel since the early 1950s (12). More recently, in the summer of 2000, an extensive outbreak occurred, affecting hundreds of people (11), dozens of horses (6), and several flocks of geese (5). However, no deaths of crocodiles were reported. This contrasts with the report from Florida (1), where WNV was isolated from dead alligators, and where hundreds of cases of sudden death had been reported in previous years; these deaths are now suspected to result, at least in part, from WNV disease.

The role of various reptile species in the epidemiology of other arboviruses such as western equine encephalitis, eastern equine encephalitis, and Venezuelan equine encephalitis is well documented (13-15). At present, the role of reptiles and amphibians in the life cycle and epidemiology of WNV is not known, and further research is necessary.

\section{Acknowledgments}

We thank Kubbi Ofer for assistance in the collection of serum samples from the crocodiles.

\section{Amir Steinman, ${ }^{*}$ Caroline Banet- Noach, $†$ Shlomit Tal,‡ Ohad Levi, ${ }^{*}$ Lubov Simanov, $\uparrow$ Shimon Perk, $\uparrow$ Mertyn Malkinson, $\dagger$ and Nahum Shpigel*}

*Hebrew University of Jerusalem Koret School of Veterinary Medicine, Rehovot, Israel; †Kimron Veterinary Institute, Bet Dagan, Israel; and $\ddagger$ Tel Aviv University Sackler Faculty of Medicine, Tel Aviv, Israel

\section{References}

1. ProMED-mail. Florida: West Nile virus identified in alligators for the first time. ProMED-mail 2002; 14 Nov: 20021114.5797. Available from: URL: http://www.promedmail.org

2. Travis D, McNamara T, Glaser A, Campbell R. A national surveillance system for WNV in zoological institutions. Available from: URL: http://www.cdc.gov/ ncidod/dvbid/westnile/conf/ppt/1a-travis. ppt

3. Nir Y, Lasowski Y, Avivi A, Goldwasser R. Survey for antibodies to arboviruses in the serum of various animals in Israel during 1965-1966. Am J Trop Med Hyg 1969;18:416-22.

4. Kostiukov MA, Gordeeva ZE, Bulychev VP, Nemova NV, Daniiarov OA. The lake frog (Rana ridibunda) - one of the food hosts of blood-sucking mosquitoes in Tadzhikistan - a reservoir of the West Nile

\title{
Dejà Vu
}

"I must have made this molecule before;

It is familiar to the core!"

Said a yeast cell emerging from mitosis,

With no experience yet in synthesis.

Then, guided by a transmigrant human gene, It assembled that "alien" protein.

Boghos L. Artinian 